\title{
Sistemas memoriais como disseminadores de informação
}

\author{
Memorial systems as disseminators \\ of information
}

Mário GOUVEIA JÚNIOR

Marcos GALINDO²

\section{Resumo}

Propõe-se, neste artigo, uma revisão da literatura cara à Ciência da Informação sobre as noções de sistema anotadas por Bertalanffy e por Luhmann, como forma de respaldar o entendimento sobre a articulação necessária entre instituições de memória como sistemas memoriais destinados à disseminação de informação. O objetivo deste trabalho, portanto, é contemplar, por meio da análise de conteúdo, aquilo que os teóricos aqui evocados têm considerado, nos últimos anos, acerca das possibilidades conferidas pelas instituições de memória no sentido de, graças a uma atuação em conjunto, tornarem-se sistemas memoriais. Como resultados alcançados a partir das presentes discussões, considera-se que a noção de sistema aplicada às instituições memoriais, pensadas como Unidades de Informação, contribui para integrar tais lugares de memória em torno do bem comum, do desenvolvimento social, possibilitado pelo acesso à informação e às responsabilidades coletivas de nos apresentarmos como bons ancestrais. O procedimento metodológico aplicado foi o da análise de conteúdo.

Palavras-chave: Disseminação da informação. Informação. Memória. Sistemas memoriais.

\begin{abstract}
We proposed a review of the literature on Information Science about the notions of system noted by Bertalanffy and by Luhmann, as way of supporting our understanding about the articulation required between memory institutions and memory systems for the dissemination of information. The objective of this work, therefore was to contemplate, by means of content analysis that which the theorists mentioned here have in recent years, considered about the possibilities offered by the memory institutions in the sense that by acting together, they become memorial systems. As results found from our discussions, we consider the notion of memorial system applied to the memory institutions, thought of as Units of Information, have contributed in the sense of integrating these places of memory around the common good, for social development, making it possible, by means of access to information and collective responsibilities to present ourselves as good ancestors. The methodological procedure used was content analysis.
\end{abstract}

Keywords: Dissemination of information. Information. Memory. Memorials systems.

\section{Introdução}

Grande marco na evolução da humanidade foi o desenvolvimento da habilidade de conceber e manipular ferramentas que ampliassem suas capacidades naturais (Martin, 2008). Mais forte e mais versátil, o homem, que dominava a linguagem e disseminava o conhecimento armazenado, tornou-se capaz de aprender com outras

\footnotetext{
1 Mestrando, Universidade Federal de Pernambuco, Programa de Pós-Graduação em Ciência da Informação. Av. Prof. Moraes Rego, 1235, Cidade Universitária, 50670-901, Recife, PE, Brasil. Correspondência para/Correspondence to: M. GOUVEIA JÚNIOR. E-mail: <gouveia_historiador@yahoo.com.br>.

2 Professor Doutor, Universidade Federal de Pernambuco, Programa de Pós-Graduação em Ciência da Informação. Recife, PE, Brasil.

Recebido em 3/2/2012, reapresentado em 5/7/2012 e aceito para publicação em 20/7/2012.
} 
experiências e aperfeiçoar informações (Galindo et al., 2011).

O advento da escrita, seguido do desenvolvimento dos suportes, propiciou a existência do documento utilizado para transmitir conhecimento entre homens que viveram em épocas distintas. Essa disseminação de conteúdos permitiu ao homem o acúmulo de informações anotadas, registradas e ensinadas ao longo de gerações. Sob essa perspectiva, vislumbram-se as instituições de memória que atuam como um dos grandes pilares da cultura ${ }^{3}$ de um país (Reis, 2006), e agem de modo a disseminar a ideia de sistemas memoriais.

Este trabalho visa a contemplar as possibilidades conferidas pelas instituições de memória para, atuando em conjunto, à guisa de um sistema, tornarem-se sistemas memoriais, isto é, atuarem todas em prol do usuário e da disseminação de conteúdos, tão peculiar à Ciência da Informação.

Para tanto, procede-se a uma revisão de literatura, contando, ainda, com procedimentos metodológicos alicerçados em análise de conteúdo: uma metodologia de pesquisa usada para descrever e interpretar o conteúdo de toda classe de documentos e textos (Bardin, 2002). Tal análise, por meio de descrições sistemáticas, quantitativas e qualitativas, auxilia na reinterpretação de mensagens, atingindo uma compreensão de seus significados para além de uma leitura comum (Minayo, 1999).

Neste artigo, evocam-se noções de sistema anotadas por Bertalanffy e por Luhmann, mencionando-se, também, a teoria do agir comunicativo de Habermas (1994). Pontua-se, ainda, a ideia de sistemas memoriais como um dos grandes pilares da cultura de um país (Reis, 2006), bem como se apresenta o conceito de memória e sua aplicabilidade no campo da Ciência da Informação.

\section{Métodos}

É por meio do método científico que a pesquisa ultrapassa as noções de senso comum, unindo o teórico ao empírico (Deslandes, 1999).
Acredita-se que a análise de conteúdo se aplique ao trabalho pelo fato de este, por vezes, ter demandado a perspicácia de um investigador que vai ao encontro das leituras especializadas, dos documentos oficiais e das falas de visitantes e gestores de instituições de memória em busca do latente, do não dito. Essa tarefa de desocultação de diversificados discursos, aplicada por meio de características hermenêuticas da análise de conteúdo, é tributária tanto do rigor da objetividade quanto da fecundidade da subjetividade (Bardin, 2002).

Desse modo, trata-se aqui de sistema e suas teorias, bem como de um breve apanhado sobre as noções de memória no campo da Ciência da Informação e da necessidade de uma organização das instituições de memória em torno de um sistema.

\section{Os sistemas e suas teorias}

Apesar de haver uma ampla variedade de definições sobre sistema, Robredo (2003) ensina que se pode pensar um sistema como um conjunto que funciona como um todo em virtude da interação de suas partes. Registre-se que ambos, as partes e o todo, dialogam entre si mediante uma relação de interdependência. Ainda nessa perspectiva, anota-se que um sistema é qualquer coisa maior que a soma de suas partes, tendo em vista que importa mais a forma como elas se relacionam entre si e as qualidades que emergem dessa relação. O mesmo autor também classifica sistema como um conjunto de relações interativas que mantém em operação, dinamicamente, um todo ao mesmo tempo em que se apresenta como o resultado inevitável de intenções organizadas, sejam essas físicas, biológicas, psicológicas, sociológicas ou simbólicas. Deve-se, no entanto, estar atento para a amplitude desse conceito, posto que, em certa medida: "[...] toda a realidade conhecida, desde o átomo até a galáxia, passando pela molécula, a célula, o organismo e a sociedade, pode ser concebida como sistema, isto é, associação combinatória de elementos diferentes" (Morin, 2011, p.19).

Ainda acerca da ideia de sistema, Morin (2011) apresenta como característica, para além de sua alocação

\footnotetext{
3 De acordo com Geertz (2008), o conceito de cultura encontra-se mergulhado em um verdadeiro pantanal conceitual, tendo em vista a grande, confusa e desencontrada profusão de definições desse termo. Esse antropólogo, a partir de uma perspectiva semiótica, e ancorando seu referencial teórico em Max Weber, defende que a cultura é, ou representa, as teias de significados construídas pelo homem em sociedade, que o amarram a esse tecido social, de modo consciente ou não, de modo passivo, reivindicativo ou participativo.
}

TransInformação, Campinas, 24(3):207-217, set./dez., 2012 
em um nível transdisciplinar, uma unidade marcada pela complexidade da noção de que um todo não se reduz à soma das partes que lhe constituem. Silva e Ribeiro (2002), por sua vez, consideram a definição de sistema como tributária do entendimento de uma estrutura complexa. Esta, por sua vez, é formada por uma gama de elementos que se inter-relacionam e dependem um do outro, assim como toda a estrutura em questão depende de todos e de cada um desses elementos. A referida estrutura, assim, é estruturada e estruturante: ela deriva dos elementos ao mesmo tempo em que os condiciona. Nesse particular, a estrutura, identificada com a totalidade, e os elementos - as partes, relacionam-se da seguinte maneira: "[...] por um lado, o sistema torna-se uma unidade na multiplicidade dos seus componentes; por outro, as partes perdem, no sistema, sua individualidade, tornando-se igualmente essenciais na formação da unidade" (Silva; Ribeiro, 2002, p.96).

De acordo com Bertalanffy (1977), a única maneira inteligível de estudar uma organização é estudá-la como sistema, uma vez que a análise dos sistemas trata a organização como um sistema de variáveis mutuamente dependentes. Por conseguinte, a teoria moderna das organizações conduz quase inevitavelmente à discussão da Teoria Geral dos Sistemas, introduzida pelo próprio Bertalanffy a partir da ideia do organismo como totalidade ou sistema. Sua teoria de princípios universais - que negavam o mecanicismo cartesiano e as noções da dinâmica do universo conforme um modelo fechado -, era apontada como aplicável aos sistemas de natureza física, biológica ou sociológica, o que ensaiava os fundamentos básicos da interdisciplinaridade (Galindo et al., 2011). Essa busca pela inter-relação entre distintos campos do conhecimento aparece quase como uma resposta à aparentemente indispensável especialização, que, em fins do século XIX, tornava-se inerente ao homem civilizado e enciclopédico.

Já nessa época, as novas demandas por informação e velocidade sugeriam não uma sociedade comandada por especialistas, que "[... ]'sabe[m]'muito bem seu mínimo rincão de universo, mas [que] ignora[m] radicalmente todo o resto" (Ortega y Casset, 2006, p.134), mas homens que tinham um campo de estudos mais largo e, ao menos, noções holísticas sobre sua área e sobre outras áreas do conhecimento. Nessa perspectiva, Chauí (2005) nos ensina que o estruturalismo proporcionou às Ciências Humanas a criação de métodos específicos para que seus objetos fossem estudados em alternativa às explicações mecânicas predominantes até então. Ademais:

A concepção estruturalista veio mostrar que os fatos humanos assumem a forma de estruturas, isto é, de sistemas que criam seus próprios elementos dando a eles sentido pela posição e pela função que ocupam no todo. As estruturas são totalidades organizadas segundo princípios internos que lhes são próprios e que comandam seus elementos ou partes, seu modo de funcionamento e suas possibilidades de transformação temporal ou histórica. Nelas, o todo não é a soma das partes nem um conjunto de relações causais entre elementos isoláveis, mas um princípio ordenador, diferenciador e transformador (Chauí, 2005, p.229).

A realidade física parecia, assim, ser a única permitida pela ciência. Esse estado de coisas, como nos mostra Bertalanffy (1977), gerou um reducionismo, ou seja, tanto a Biologia quanto as Ciências Sociais e as ciências ditas do comportamento eram vistas, pensadas e regidas de acordo com os modelos e conceitos da física. Prevalecia, então, dentro e fora das ciências da natureza, o mecanicismo (Descartes, 2003): paradigma que só se alteraria quando a ambiguidade e a complexidade dos fenômenos observados exigiram mais do que fórmulas explicativas facilmente encaixáveis (Kuhn, 1979, 1990). Nesse sentido, acrescente-se que reflexões acerca de uma espécie de negligência por parte do mecanicismo ante muitos problemas apresentados pelas Ciências Biológicas, Sociais e do Comportamento acarretaram novas abordagens em torno da noção de organismo.

Contemplava-se, a partir desse viés, o entendimento de um sistema aberto em que o organismo não é um sistema estático fechado, mas em ininterrupta transformação, correlação e troca com o meio externo, como a própria vida, em que"o homem não é um recebedor passivo de estímulos provenientes do mundo exterior, mas em sentido muito concreto cria seu universo" (Bertalanffy, 1977, p.257).

Aliás, no caso dos sistemas abertos, os estímulos provenientes do meio podem modificar a estrutura do sistema, levando à seleção de novas estruturas, conforme pontua Luhmann (2011). Iniciou-se, então, uma tendência 
de pensamento, externalizada pelas ciências modernas, que refutava os esquemas cartesianos e mecanicistas de unidades isoláveis e priorizava abordagens organísmicas no sentido de pensar os sistemas como elementos em perene relação de interação e interdependência. A essa verdadeira transformação, Bertalanffy (1977) chamou de Revolução Organísmica. Essa confluência para um pensamento holístico levou ao entendimento de que os fenômenos sociais devem ser considerados como sistemas e não como a mera soma de átomos sociais, uma vez que "[... to toda ciência social é a ciência dos sistemas sociais" (Bertalanffy, 1977, p.259).

A ciência contemporânea, desse modo, adotou tal perspectiva, buscando um exame das interações e investigando setores da natureza cada vez maiores ao invés de isolar os fenômenos em contextos particulares. Nesse contexto, a teoria geral dos sistemas apresenta-se como: "[...] um instrumento útil capaz de fornecer modelos a serem usados em diferentes campos e transferidos de uns para outros, salvaguardando-se ao mesmo tempo do perigo das analogias vagas, que muitas vezes prejudicaram o progresso nesses campos" (Bertalanffy, 1977, p.57).

De acordo com Luhmann (2011) - para quem os sistemas podem ser orgânicos, psíquicos ou sociais -, não existe propriamente uma teoria geral de sistemas, como postulara Bertalanffy. No próprio campo da Sociologia, não se pode pensar numa teoria geral dos sistemas sociais; aquele teórico concebe, todavia, a existência de modelos gerais da teoria dos sistemas que repercutiram no campo da Sociologia. Desse modo, os modelos indicados por Luhmann (2011, p.63) são: o do equilíbrio, marcado pela relação estabilidade/perturbação; o do desequilíbrio, gerido pela ideia de que no desequilíbrio os sistemas adquirem sua estabilidade; e o do intercâmbio, de energia, para os sistemas orgânicos, e de informação, para os sistemas de sentido. Nesse último, aliás, a entropia sugere troca entre sistema e meio, o que leva à ideia dos sistemas abertos, que "[... ] respondem a essa referência teórica, na medida em que os estímulos provenientes do meio podem modificar a estrutura do sistema: uma mutação não prevista, no caso do biólogo; uma comunicação surpreendente, no social".

Dessa teoria dos sistemas abertos - responsável pela mudança de paradigma da distinção do todo e das partes para a distinção de sistemas e meio -, derivam outras três teorias subsidiárias: input/output; feedback positivo; e feedback negativo. Para o primeiro desses modelos, o sistema, e não o meio, tem autonomia para decidir quais fatores determinantes propiciam o intercâmbio. Os outros dois modelos em questão, por sua vez, são tributários da ideia de feedback, que, nesse caso, representa uma alternativa à demanda em se "alcançar outputs relativamente estáveis diante de um meio instável ou de situações variáveis" (Luhmann, 2011, p.68). Seu princípio básico se revela em "como funciona um preceito do sistema ao se produzir uma distância considerável no meio, obrigando o sistema a reagir para obter a estabilidade" (Luhmann, 2011, p.69). Desse modo, enquanto o feedback negativo se dispõe a diminuir as distâncias, o positivo indica seu aumento. Ainda nessa linha de pensamento, pode-se acrescentar que:

[...] já não se trata, em primeira instância, da estabilidade do sistema, mas das mudanças que um sistema pode suportar: que quantidade de transformações é possível introduzir nele, sem colocá-lo em perigo? Ou, dito de outra forma: se realmente existem mecanismos para aumentar as distâncias, até onde se pode chegar, sem detrimento substancial do sistema? (Luhmann, 2011, p.71).

A teoria dos sistemas apresentada por Luhmann em oposição à de Bertalanffy, que se pautava nas relações entre o todo e as partes -, está baseada na diferença entre o sistema e o meio. Desse modo, paradoxalmente, o sistema cria sua própria unidade, à medida que realiza uma diferença. Ademais, "o meio é um momento constitutivo dessa diferença e, por isso, não é menos importante do que o próprio sistema" (Luhmann, 2011, p.259). Desse modo:

O meio pode conservar aspectos que podem ser mais importantes para o sistema (seja qual for o ponto de vista) do que os seus próprios componentes; mas também a alternativa contrária é teoricamente compreensível. Graças à distinção entre sistema e meio, é possível conceber o homem como parte do meio social, de maneira mais complexa e, ao mesmo tempo, mais livre, do que o meio, comparativamente ao sistema, constitui o campo de distinção de maior complexidade e menor ordem (Luhmann, 2011, p.260). 
É o mesmo Luhmann (2011) que registra que alguns teóricos contrapõem, incisivamente, a teoria dos sistemas à teoria da ação, como dois paradigmas contrários, apresentando a justificativa de que enquanto esta última se volta para o indivíduo na qualidade de sujeito - englobando os aspectos psíquicos e orgânicos daquele que age -, aquela designa realidades macrossociais, conservando um caráter de elevada abstração. Em resposta a essa linha de pensamento, Luhmann, considera que a ação só é possível sob a forma de sistema: action is system. Afirma, ainda, que a construção de estruturas sociais se realiza sob a forma de sistema, sendo este, por sua vez, edificado pela ação. Esses dois conceitos formariam, então, um par indissociável e não um par de opostos.

Para Luhmann (2011), antes mesmo de os indivíduos - mero elemento no contexto da ação -, agirem, a sociedade já está integrada pela moral, pelos valores e pelos símbolos normativos. Em outras palavras, a sociedade só existe por estar integrada sob a forma de sistema; e, desse modo, a ação realiza-se quando já existem valores coletivos estabelecidos e socialmente reconhecidos e aceitos. Por esse viés, explica-se o social como:

[...] uma rede de operações que gera uma fenomenologia de autopoiesis. Nessa perspectiva, é muito difícil que o conceito de ação seja adequado para definir o operador social, já que a ação pressupõe, ao menos no entendimento comum, um processo de atribuição que nem sempre desemboca em um acontecimento de socialização. A ação pode também ser descrita como um acontecimento solitário, individual, sem nenhum tipo de repercussão social (Luhmann, 2011, p.91).

Analisando-se criticamente a teoria dos sistemas sociais, postulada por Habermas (1989), por sua vez, constrói-se um conceito de ação sociocomunicativa com ênfase no sujeito e suas capacidades de interação, autonomia e responsabilidade. Esse conceito foi chamado por Habermas (1989, p.166) de agir comunicativo e definido por ele como:

[...] um processo circular no qual o ator é duas coisas ao mesmo tempo: ele é o iniciador, que domina as situações por meio de ações imputáveis; ao mesmo tempo, ele é também o produto das tradições nas quais se encontra, dos grupos solidários aos quais pertence e dos processos de socialização nos quais se cria.
Na perspectiva de sua teoria do agir comunicativo, desse modo, Habermas percebe o homem organizacional como um indivíduo livre, inteligente e autônomo; o que, por conseguinte, proporciona-lhe a capacidade de agir utilizando a linguagem para se comunicar com seus pares na busca de um entendimento mútuo. Nessa mesma linha de pensamento, Freire $(2002,2011)$, que entende o processo de orientação do homem no mundo por meio de pensamento-linguagem, envolvendo desejo e trabalho-ação transformadora sobre o mundo, afirma que:

[...] os homens são seres da práxis. São seres do quefazer, diferentes, por isto mesmo, dos animais, seres do puro fazer. Os animais não 'admiram' o mundo. Imergem nele. Os homens, pelo contrário, como seres do quefazer 'emergem' dele, e, objetivando-o, podem conhecê-lo e transformá-lo com seu trabalho [já que] [...] seu fazer é ação e reflexão. É práxis. É transformação do mundo (Freire, 2011, p.167).

Tais conceitos de autonomia, ação coletiva e interação ainda serão contemplados neste trabalho. Por hora, passa-se à abordagem das seguintes questões: para que servem e a quem servem os sistemas memoriais?

\section{Memória}

Conforme McLuhan (1977), quando o homem caminhou da oralidade para a escrita, a assimilação e a interiorização dessa nova tecnologia, que representou o alfabeto fonético, transladaram o homem do mundo mágico da audição para o mundo neutro da visão. Essa magia referente à audição, por sinal, parece dialogar com a arte da narrativa, que dá indícios de extinção desde o surgimento do romance, essencialmente vinculado ao livro impresso e por ele difundido (Benjamim, 1994). Com o advento da escrita e a posterior invenção de Gutenberg, aqueles que dominavam essa tecnologia, para além de comunicarem suas ideias por meio de signos visuais, também poderiam produzir um registro perene desses signos e sinais, e, dessa forma, criar uma memória exterior à própria mente (McGarry, 1999). Essa demanda se faria necessária à medida que a quantidade de informação se tornasse superior à capacidade humana de guardá-las todas na memória.

Seria preciso, então, solucionar o problema do armazenamento de informações em suportes palpáveis 
e duráveis (Le Coadic, 2004). Éassim que a arte da memória, oriunda de uma tradição muito antiga, seria subjugada pelos excessos de papel e, a posteriori, pelos bancos de dados e pela Internet, que a tornaram supérflua e inútil (Rossi, 2010). Surgiram, assim, em fins do século XVIII, o que Leibniz chamaria de memórias de papel e a necessidade por lugares de memória (Nora, 1993). Nessa mesma época, um dos principais objetivos da ilustração era fazer do livro uma ferramenta de transformação da sociedade, modelando hábitos por meio de sua leitura, verbal ou icônica, e ditando a substituição das leis consuetudinárias (Certeau, 2008).

As últimas décadas do século XIX marcam o momento histórico em que o homem se dedicou às invenções das tradições em massa; as invenções oficiais de ordem política trataram de dar conta das profundas e rápidas transformações sociais da época. Exemplos disso, na França, foram as instituições educacionais laicas, a invenção de cerimônias públicas e a produção em massa - numa proporção maior do que aquela verificada nos anos imediatamente subsequentes à Revolução de 1789 -, de monumentos públicos, já que: "grupos sociais, ambientes e contextos sociais inteiramente novos, ou velhos, mas incrivelmente transformados, exigiam novos instrumentos que assegurassem ou expressassem identidade e coesão social, e que estruturassem relações sociais" (Hobsbawm, 2008, p.272).

De acordo com Nora (1993), graças ao volume de informação produzido espontaneamente pela sociedade, seus meios técnicos de reprodução e de conservação, e, sobretudo, à superstição e ao respeito ao vestígio, vivemos na época que mais se produziram arquivos, pois, à medida que a memória tradicional desaparece, somos forçados a acumular sinais visíveis do que existiu, criando ambientes artificiais que abrigariam imagens cuja função seria a de "[... t trazer algumas coisas à memória" (Rossi, 2010, p.23).

Foi assim que arquivos, bibliotecas e museus se fizeram necessários porque, conforme nos ensina Nora (1993), não habitamos mais nossa memória, por isso a necessidade de lhe consagrar espaços de produção e divulgação que se enraízam no concreto, no gesto, na imagem, no objeto, materializando-a. Esses redutos da memória representam os rituais sagrados de uma sociedade desritualizada e dessacralizada, que só é capaz de lembrar uma ínfima parcela daquilo que poderia ter necessidade de lembrar.

Le Goff (2003) nos ensinou a pensar a memória como um fenômeno social ${ }^{4}$, tributário tanto dos sistemas dinâmicos de informação quanto do comportamento narrativo dos sujeitos em sociedade. A memória, percebida como propriedade de conservar certas informações, é geralmente associada a um conjunto de funções psíquicas, por meio das quais se pode atualizar impressões ou informações passadas, que, por sua vez, têm o poder de contribuir para o fortalecimento de uma comunidade e até para a autoafirmação dos sujeitos em torno da ideia de pertencimento a determinados grupos sociais. Desse modo:

A memória é um elemento essencial do que se costuma chamar identidade, individual ou coletiva, cuja busca é uma das atividades fundamentais dos indivíduos e das sociedades de hoje, na febre e na angústia. Mas a memória coletiva não é somente uma conquista, é também um instrumento e um objeto de poder (Le Goff, 2003, p.469).

Acerca das noções de memória coletiva, vale lembrar o estudo de Halbwachs (2006), que indica não a existência de uma memória coletiva, mas de muitas memórias coletivas. Nesse sentido, todas as nossas lembranças são coletivas e nos são lembradas pelo outro, mesmo que tais lembranças aludam a momentos em que somente nós estivemos envolvidos ou a objetos que somente nós vimos. Isso ocorre porque nunca estamos sozinhos, tendo em vista que nossos atos e pensamentos se explicam por uma natureza de ser social e pelo fato de que não deixamos de estar encerrados em alguma sociedade. Desse modo, "são os indivíduos que se lembram, enquanto integrantes do grupo" (Halbwachs, 2006, p.69).

Vale enfatizar que, de acordo com o postulado por Halbwachs (2006), essa memória coletiva não se configura como exercício de uma forma específica de dominação ou violência simbólica, uma vez que a já mencionada seletividade da memória conta com um

\footnotetext{
${ }^{4}$ A memória se constitui como um fenômeno social em virtude de se tratar de comunicação a outrem de uma informação na ausência do acontecimento ou do objeto que constitui o seu motivo (Le Goff, 2003, p.421).
} 
processo de negociação, que visa a conciliar as memórias individuais com as memórias coletivas.

Sob a ótica de Ricoeur (2007), em sua abordagem de uma memória mais histórica e voltada para a evocação, para a lembrança e para a recordação, a memória é do passado e só existe com o passar do tempo. Na perspectiva da Ciência da Informação, contudo, a memória é percebida como ato de armazenamento e preservação de informação tanto para a sociedade atual quanto para as do porvir. Desse modo, enquanto a memória histórica alude ao passado ${ }^{5}$, ao que foi feito ou dito, a memória, para o presente campo de estudos, é projetada para o futuro, ou seja, para o que está sendo feito ou precisa ser feito, objetivando a preservação e a disseminação de informação.

Tratando do lugar da memória no processo evolutivo do homem, Menezes (2007), por sua vez, associa a abstração e a articulação ao desenvolvimento da capacidade craniana. Enquanto a abstração basicamente seria o processo por meio do qual transformamos o sensível no inteligível, à articulação podemos atribuir noções de causa-consequência que nos tornaram hábeis no sentido de prever situações ou de provocá-las de acordo com nossas necessidades.

Para Menezes (2007), a memória e a linguagem, bem como a imaginação, são importantes ferramentas entre a abstração e a articulação em virtude de serem responsáveis por uma espécie de sedimentação das aprendizagens daquelas duas capacidades; do contrário, nos comportaríamos como os tigres da metáfora de Ortega y Gasset (2006), que precisam agir, a cada dia, como se fossem os primeiros de sua espécie, posto que não são capazes de recordar nem de transmitir aquilo que aprenderam no dia anterior.

Ainda sobre a memória, Menezes (2007) afirma que ela não só transmite informação, conhecimento e significações, mas cria significados com os quais o cérebro trabalha. Nesse caso, parece válido considerar que tais significados, por serem construídos, são dinâmicos e tão mutáveis e múltiplos quanto a identidade do indivíduo e suas possibilidades subjetivas. Em seus estudos sobre a memória, Menezes (2007) enumerou cinco paradoxos:

1) A voga e a crise da memória: indica a presença da memória, a enxurrada de informação e o absurdo de se pretender guardar tudo na mente ou em lugares. Nesse particular, a hiperinformação produz a desinformação, isto é, a quantidade de informação que se põe à disposição da sociedade só pode ser consumida de modo superficial e precário.

2) Memória-amnésia: a memória sugere um mecanismo de seleção e esquecimento programado, já que seria impossível para o homem o pensamento e a lembrança sem o olvido. Há, entretanto, os esquecimentos programados e inevitáveis e os provocados e outorgados contra pessoas, instituições e civilizações. Seriam esses mecanismos repressivos e caracterizadores daquilo que não podia ser visto nem podia ser dito em várias épocas.

3) Relação indivíduo-sociedade: salienta a memória coletiva, não como o somatório das memórias coletivas, mas como sustentáculo das redes de interação e seus circuitos de comunicação. Os espaços públicos e os monumentos foram criados com a intenção de marcar e legitimar a celebração dessa memória coletiva. Todavia, com a redução das funções e dos sentidos dos espaços públicos, os monumentos perderam sua natureza coletiva para o habitante das cidades, que passou de cidadão a passante - aquele que apenas passa pelos espaços e não os pratica mais - e, depois, a passageiro - aquele que é levado a atravessar os espaços, de um ponto a outro, anulando o que existe nesse intervalo.

4) Objetividade-subjetividade: citando considerações de Nora (1993) acerca das necessidades do homem por lugares de memória, Menezes traz, em contrapartida a esse pensamento, a ideia dos espaços de massa como formadores e disseminadores da memória na atualidade. Em sua perspectiva, talvez o principal deles seja a Internet - um novo lugar de memória em ação e transformação permanentes. Não basta, todavia, ao homem contemporâneo mergulhar nesse mundo de possibilidades da Web ao sabor dos ventos do hipertexto. Antes de sabermos as respostas, precisamos estar conscientes de quais perguntas devem ser feitas. A memória

\footnotetext{
5 Sem que tal afirmação implique a indesejada ideia de que a História seja uma ciência do passado, já que parece absurdo pensar que o passado enquanto tal seja objeto de ciência. Nesse particular, a História aparece como uma ciência dos homens no tempo e que incessantemente tem a necessidade de unir o estudo dos mortos aos dos vivos - do passado e do presente (Bloch, 2001).
} 
é, assim, entendida como um campo de negociação em que devemos deixar de lado a oposição entre a objetividade e a subjetividade para, daí, colhermos os seus melhores frutos.

5) Passado-presente: oposição entre passado e presente. Este último, aliás, é apontado como o tempo da memória, porque é no presente que se constrói a memória. Nessas relações entre tempos e memória, Menezes (2007) postula que a contemporaneidade reúne, em um tempo sincrônico, diversas temporalidades que operam a memória.

\section{Sistemas memoriais para quem?}

Uma instituição, seja ela científica ${ }^{6}$, tecnológica ou social, é formada por pessoas que, ao executarem serviços distintos atuando em conjunto, acabam por formar um organismo. Por sua vez, um conjunto de organismos que interagem e trocam experiências, materiais e métodos, em torno de um objeto comum, pode representar um sistema. E se tal sistema está ligado à memória e à informação - com base na ideia de que "os sistemas são fontes de informação e a informação é capaz de construir um sistema" (Robredo, 2003, p.110) -, então se pode introduzir nas considerações presentes a ideia de sistemas memoriais, que são chamados por Silva e Ribeiro (2002, 2011) de sistemas artificiais convencionais, uma vez que implicam a intervenção humana e suas relações organizativas e dinâmicas, dispostas de modo a tecer uma rede. De forma análoga, Reis (2006) considera que um dos grandes pilares da cultura de um país é o círculo das instituições culturais.

Vai ao encontro dessa linha de pensamento o modelo de sistema memorial que sugere a leitura do conjunto de segmentos interdependentes e interoperantes de missão memorial alocado no universo de arquivos, bibliotecas e museus, bem como outros serviços públicos e privados. Nesse bojo estão incluídas todas as instituições atuantes nos campos da conservação, preservação e acesso aos bens do patrimônio memorial (Galindo, et al., 2011).
Um exemplo desses sistemas artificiais convencionais, aqui tratados também como sistemas memoriais, é o Sistema Brasileiro de Museus (SBM), criado a partir do Decreto no 5.264/2004, com a responsabilidade de promover a interação entre as instituições de memória e seus profissionais - em prol de seu desenvolvimento - e de valorizar, registrar e disseminar conhecimento, cultura e memória, por meio de suas práticas museológicas (Brasil, 2004).

Os museus são apontados também como instituições sem fins lucrativos que conservam, investigam, comunicam, interpretam e expõem, para fins de preservação, estudo, pesquisa, educação, contemplação e turismo, conjuntos e coleções de valor histórico, artístico, científico, técnico ou de qualquer outra natureza cultural, abertas ao público, a serviço da sociedade e de seu desenvolvimento (Instituto de Patrimônio Histórico e Artístico Nacional, 2005). São instituições de memória que têm como princípios a valorização da dignidade dos sujeitos, a promoção da cidadania, o cumprimento da função social, a valorização e a preservação do patrimônio cultural e ambiental, a universalidade do acesso, o respeito e a valorização à diversidade cultural e o intercâmbio institucional (Brasil, 2009).

Os museus, de acordo com o SBM, por sua vez, são percebidos ainda como casas que guardam e apresentam sonhos, sentimentos, pensamentos e intuições que ganham corpo por meio de imagens, cores, sons e formas. Representam, ainda, pontes e janelas que ligam e desligam mundos, tempos, culturas e pessoas diferentes. Numa palavra, evidenciam conceitos e práticas em metamorfose.

Para Souza (2009), o museu é percebido como instância de representação da memória social e espaço onde a informação é entendida como insumo cultural, terreno mais que apropriado para o desenvolvimento de estudos e ações diretamente ligados à informação. Nesse sentido, o museu é entendido como o grande repositório da cultura e dos elementos mais marcantes da natureza humana. É também o único organismo que dissemina conceitos, ilustra, distrai e deleita (Costa, 2002). Os museus,

\footnotetext{
6 Percebe-se a impossibilidade de se fazer ciência sem o elemento humano, visto que toda ciência está estreitamente vinculada às necessidades e às atividades do homem. Numa palavra, proceder com a separação entre ser e pensamento, homem e natureza, sujeito e objeto, significa cair em uma forma de religião ou abstração carente de sentido (Gramsci, 1984). A própria atividade científica - atrelada às impressões humanas e partindo do senso comum -, denota uma natureza social à medida que seu arcabouço de conhecimento é produzido, registrado, acumulado e disseminado a cada geração.
} 
ainda, apresentam-se como espaços de organização e evocação de referências culturais que contribuem para o desenvolvimento dos sujeitos sociais ao mesmo tempo em que se tornam polos irradiadores de uma dinâmica social que atua na identidade, filiação e legitimidade, tomando, nessa tarefa, o passado e a memória como propulsores dessa reflexão (Jeudy, 1990).

Os museus, por fim, devem ser percebidos como instituições de memória interiorizadas pelos indivíduos e dispostas de modo a facilitar ao máximo o acesso, a autonomia individual e as possibilidades de participação efetiva em todo poder explícito existente na sociedade, conforme nos ensina Castoriadis (1992).

O SBM é definido também como uma rede organizada de instituições museológicas, baseada na adesão voluntária, configurada de forma progressiva e que visa à coordenação, articulação, mediação, qualificação, diálogo e cooperação entre museus. Esse estado de coisas torna tais instituições representativas da diversidade étnica e cultural do Brasil.

É assim que o SBM foi concebido e está disposto, de modo a estimular a articulação entre o poder público e a sociedade civil, aumentando a visibilidade institucional ao mesmo tempo em que favorece a melhor gestão e configuração do campo do museu. Devemos registrar também que aquele mesmo decreto de 2004 esclarece que as referidas instituições de memória são entidades envolvidas com o patrimônio cultural que disponibilizam ao público possibilidades de ampliação do campo de construção de sua identidade, como recurso de inclusão social pela educação -, por meio de acervos e exposições e do estímulo à produção de conhecimento irmanada a oportunidades de lazer (Brasil, 2004).

Promover a articulação entre as instituições participantes do SBM, sem desrespeitar a autonomia de cada museu, é um dos objetivos desse sistema, que, entre outras disposições, ainda busca estimular a criação de programas, projetos e atividades museológicas ligadas à valorização do patrimônio cultural de comunidades populares e tradicionais. É pertinente enfatizarmos que essa noção de sistema memorial começou a fazer parte da agenda política brasileira a partir de 2003, quando novos marcos conceituais e práticos foram estabelecidos para a gestão da cultura brasileira, tirando-a das margens políticas governamentais.
De acordo com Coelho Neto $(1986,1997)$, de modo mais restrito, as políticas culturais representam um conjunto de iniciativas que visam a promover a produção, a distribuição e o uso da cultura; visam à preservação e à divulgação do patrimônio histórico; e ao ordenamento do aparelho burocrático por elas responsável. Ainda nesse contexto, Canclini (1987) acrescenta que uma política cultural não se restringe a ações pontuais; ocupa-se, pelo contrário, da ação cultural em um sentido contínuo na vida das pessoas, em todos os espaços sociais, evidenciando um processo interativo entre a atuação, os movimentos sociais e o funcionamento do aparelho político-administrativo.

A cultura, então, começa a ser percebida pelo Estado como um conceito ampliado - que ultrapassa a ênfase nas artes consolidadas e se afasta dos ideais de nacionalismo e suas glórias -, e passa a ser identificada como fenômeno social e humano de múltiplos sentidos, como manifestações que têm força simbólica e reconhecimento nas sociedades (Brasil, 2010).

\section{Considerações Finais}

Ao final das considerações presentes acerca de memória, noções de sistema e de sistemas memoriais, cabem, ainda, alguns pontos a serem observados. Inicialmente, deve-se registrar que a memória percebida à luz da Ciência da Informação é um conjunto de ações feitas a partir do presente com o objetivo de iluminar as gerações futuras.

Nesse sentido, como resultados alcançados a partir de discussões, considera-se que a noção de sistema aplicada às instituições memoriais, pensadas como Unidades de Informação, contribui para integrar tais lugares de memória em torno do bem comum, do desenvolvimento social possibilitado por meio do acesso à informação e das responsabilidades coletivas de nos apresentarmos como bons ancestrais.

Deve-se enfatizar que os sistemas memoriais têm como missão apresentar-se à sociedade como instrumentos catalisadores da democratização de acesso do público à memória, o que garante a devida concessão de poder social àqueles que, ao longo do tempo, têm sido impedidos de narrar suas histórias, erigir seus patrimônios 
e disseminar sua cultura e consumi-la. Esse consumo está pautado tanto no acesso a bens artísticos quanto à informação, implicando, assim, o direito de buscar informação, tecer opiniões, comunicar-se com o outro e tomar parte do acervo e do repertório simbólico da coletividade.

Como resultados das investigações, pode-se identificar o sistema como um conjunto que funciona como um todo a partir da interação entre suas partes, e que o funcionamento desse sistema o torna maior e mais complexo do que a mera soma dessas partes, pois importa mais a forma, a força e a qualidade dessas relações do que sua quantidade. Nesse caso, ainda, vale enfatizar que a interdependência comunga com a interoperância de cada peça do conjunto. A noção de sistema, portanto, sugere uma estrutura que é, ao mesmo tempo, estruturada e estruturante, ou seja, essa estrutura determina os elementos que, em contrapartida, a condicionam. É dessa forma que se passa a considerar, por exemplo, os fenômenos sociais como sistemas, pois eles, simultaneamente, dependem dos atores sociais e os condicionem.

Vê-se que o sistema aqui tratado foge da lógica cartesiana e se apresenta como um organismo aberto e entrópico, o que sugere ininterruptas transformações e trocas com o meio externo, cuja influência pode até modificar a estrutura do sistema. Desse modo, é apropriado afirmar que o meio e o sistema se complementam em suas distinções.

Contemplam-se, ainda, as discussões em torno das contraposições entre a teoria dos sistemas e suas realidades macrossociais, e a teoria da ação e suas perspectivas voltadas para os sujeitos. Para determinada corrente teórica, o par sistema-ação é enxergado por meio de uma noção dialógica de complementaridade e mesmo indissociabilidade; mas, nesse caso, defende-se que o sistema preexiste à ação. Outro grupo de pensadores enaltece e prioriza a ação. Tal grupo pensa o homem organizacional como um sujeito dotado de liberdade, inteligência e autonomia: atributos que lhe proporcionam agir por meio da linguagem para, assim, comunicar-se com seus pares em prol de um entendimento mútuo e de um trabalho-ação que transforme o mundo - ou o sistema.

No tocante à memória e aos seus debates, identificou-se essa como um fenômeno social, tributário dos sistemas dinâmicos de informação e do comportamento narrativo dos sujeitos em sociedade, porque a memória não se restringe à transmissão de informação, conhecimento e significações, mas cria significados - dinâmicos por natureza -, com os quais o cérebro trabalha.

Define-se, por fim, sistemas memoriais como o conjunto de segmentos interdependentes e interoperantes de missão memorial alocado no universo de arquivos, bibliotecas, museus e todas as demais instituições atuantes nos campos da conservação, preservação e acesso aos bens do patrimônio memorial. Identificou-se o SBM como um importante esforço empreendido em favor da promoção da comunicação e do compartilhamento de conteúdos e responsabilidades de registro, valorização e disseminação de conhecimento, cultura e memória para uma comunidade cada vez mais interessada na construção de seus valores, de suas histórias e de suas identidades - todos eles múltiplos -, formadores de sua efetiva cidadania.

Cidadania esta que começa, então, a se configurar por meio da ampliação e da multiplicação dos espaços públicos de educação, de encontro com diferenças, de memória coletiva e poder, de construção de identidades, de diálogo, debate e transformação social. Essa perspectiva parece a principal motivação e função de ser dos sistemas memoriais - um conjunto integrado e interoperante de Unidades de Informação, que, atuando em conjunto, podem contribuir de modo mais enfático para disseminar informação.

\section{Referências}

BARDIN, L. Análise de conteúdo. Lisboa: Edições 70, 2002.

BENJAMIM, W. Magia e técnica, arte e política: ensaios sobre a literatura história da cultura. 7.ed. São Paulo: Brasiliense, 1994.

BERTALANFFY, L. Teoria geral dos sistemas. 3.ed. Petrópolis, Vozes, 1977.
BLOCH, M. Apologia da história, ou, o ofício do historiador. Rio de Janeiro: Zahar, 2001.

BRASIL. Decreto no 5.264, de 5 de novembro de 2004. Institui o sistema brasileiro de museus e dá outras providências. Diário Oficial da União, 8 nov. 2004. Disponível em: <http://www.cultura.gov.br/site/wp-content/uploads/2007/ 10/decreto-5264.pdf>. Acesso em: 7 jan. 2011. 
BRASIL. Lei no 11.904, de 14 de janeiro de 2009. Institui o estatuto de museus e dá outras providências. Diário Oficial da União, 15 jan. 2009. Disponível em: <https://www.planalto.gov. br/ccivil_03/_ato2007-2010/2009/lei/l11904.htm>. Acesso em: 20 dez. 2011.

BRASIL. Ministério da Cultura. Política nacional de museus: relatório de gestão 2003-2010. Brasília: MinC, 2010.

CANCLINI, N.G. (Org.). Políticas culturales en América Latina. 3.ed. México: Grijalbo, 1987.

CASTORIADIS, C. Poder, política, autonomia. In: CASTORIADIS, C. O mundo fragmentado. Rio de Janeiro: Paz e Terra, 1992.

CERTEAU, M. A invenção do cotidiano: artes de fazer. 15.ed. Petrópolis: Vozes, 2008.

CHAUÍ, M. Convite à filosofia. 13.ed. São Paulo: Ática, 2005.

COELHO NETO, J.T. Usos da cultura: políticas de ação cultural. Rio de Janeiro: Paz e Terra, 1986.

COELHO NETO, J.T. Dicionário crítico de política cultural. São Paulo: lluminuras, 1997

COSTA, L.M. De museologia, arte e políticas de patrimônio. Rio de Janeiro: IPHAN, 2002.

DESCARTES, R. Discurso do método. São Paulo: Escala, 2003.

DESLANDES, S.F. A construção do projeto de pesquisa. In: MINAYO, M.C.S. (Org.). Pesquisa social: teoria, método e criatividade. 18.ed. Petrópolis: Vozes, 1999. p.31-50.

FREIRE, P. Pedagogia da autonomia: saberes necessários à prática educativa. 24.ed. São Paulo: Paz e Terra, 2002.

FREIRE, P. Pedagogia do oprimido. 50.ed. Rio de Janeiro: Paz e Terra, 2011

GALINDO, M.; MIRANDA, M.O.; BORBA, V.R. A memória e os sistemas memoriais. In: ENCONTRO NACIONAL DE PESQUISA EM CIÊNCIA DA INFORMAÇÃO, 12., 2011, Brasília. Anais.. Brasília: UnB, 2011. p.3328-3339.

GEERTZ, C. A interpretação das culturas. Rio de Janeiro: LTC, 2008

GRAMSCI, A. Concepção dialética da história. 5.ed. Rio de Janeiro: Civilização Brasileira, 1984.

HABERMAS, J. Consciência moral e agir comunicativo. Rio de Janeiro: Tempo Brasileiro, 1989.

HABERMAS, J. A crise de legitimação do capitalismo tardio. 2.ed. Rio de Janeiro: Tempo Brasileiro, 1994.

HALBWACHS, M. A memória coletiva. São Paulo: Centauro, 2006.

HOBSBAWM, E. A produção em massa de tradições: Europa, 1870 a 1914. In: HOBSBAWM, E.; RANGER, T. (Org.). A invenção das tradições. 6.ed. Rio de Janeiro: Paz e Terra, 2008. p.271-316.

INSTITUTO DE PATRIMÔNIO HISTÓRICO E ARTÍSTICO NACIONAL. Ministério da Cultura. Definição de museu. 2005. Disponível em: <http://museus.gov.br/museu/>. Acesso em: 2 jun. 2012
JEUDY, H.P. Memórias do social. Rio de Janeiro: Forense Universitária, 1990.

KUHN, T. A função do dogma na investigação científica In: DEUS, J.D. (Org.). A crítica da ciência: sociologia e ideologia da ciência. 2.ed. Rio de Janeiro: Zahar, 1979. p.53-80.

KUHN, T. A estrutura das revoluções científicas. 3.ed. São Paulo: Perspectiva, 1990.

LE COADIC, Y.F. O objeto: a informação In: LE COADIC, Y.F. A ciência da informação. 2.ed. Brasília: Briquet de Lemos, 2004.

LE GOFF, J. História e memória. 5.ed. Campinas: Unicamp, 2003.

LUHMANN, N. Introdução à teoria dos sistemas. 3.ed. Petrópolis: Vozes, 2011.

MARTIN, G. Pré-história do nordeste do Brasil. 5.ed. Recife: UFPE, 2008.

McGARRY, K. O contexto dinâmico da informação. Brasília: Briquet de Lemos, 1999.

MCLUHAN, M. A galáxia de Gutenberg: a formação do homem tipográfico. São Paulo: Nacional, 1977.

MENEZES, U.B. Os paradoxos da memória. In: MIRANDA, D.S. Memória e cultura: a importância na formação cultural humana. São Paulo: Sesc, 2007. p.13-33.

MINAYO, M.C.S. Ciência, técnica e arte: o desafio da pesquisa social. In: MINAYO, M.C.S. (Org.). Pesquisa social: teoria, método e criatividade. 18.ed. Petrópolis: Vozes, 1999. p.9-29.

MORIN, E. Introdução ao pensamento complexo. 4.ed. Porto Alegre: Sulina, 2011.

NORA, P. Entre memória e história: a problemática dos lugares. Projeto História, n.10, p.7-28, 1993.

ORTEGA Y GASSET, J. A rebelião das massas. 2.ed. São Paulo: Martins Fontes, 2006.

REIS, A.C.F. Marketing cultural e financiamento da cultura: teoria e prática em um estudo internacional comparado. São Paulo: Thomson Learning, 2006.

RICOEUR, P. A memória, a história, o esquecimento. Campinas: Unicamp, 2007

ROBREDO, J. Da ciência da informação revisitada aos sistemas humanos de informação. In: ROBREDO, J. Da ciência da informação revisitada aos sistemas humanos de informação. Brasília: Thesaurus, 2003.

ROSSI, P. O passado, a memória, o esquecimento: seis ensaios da história das ideias. São Paulo: Unesp, 2010.

SILVA, A.M.; RIBEIRO, F. Das ciências documentais à ciência da informação: ensaio epistemológico para um novo modelo curricular. Porto: Afrontamento, 2002.

SILVA, A.M.; RIBEIRO, F. Paradigmas, serviços e mediações em ciência da informação. Recife: Néctar, 2011.

SOUZA, D.M.V. Informação e construção de conhecimento no horizonte museológico. DataGramaZero, v.10, n.6, 2009. Disponível em: <http://www.dgz.org.br>. 
